\title{
Taking Concept Mapping (CM) forward with socially mediated structured approaches
}

\section{Maja Jankowska}

University of Bedfordshire, UK

\section{Abstract}

There is substantial research evidence (e.g. Nygaard and Holtham, 2008, 2009) to indicate that students' active engagement in co-constructing knowledge, and taking responsibility for their own learning, is key to their achievement and development. This chapter will explore Concept Mapping (CM) not only as one means of gathering research data but also - and most importantly - as a powerful technique to support reflection and offer space for internal dialogue about each student's personal development.

Concept maps were gathered from a sample of students on a postgraduate business programme. In addition to the data from the concept maps themselves, semi-structured individual interviews were conducted with part of the sample to follow-up and illuminate the $\mathrm{CM}$ process, as they seemed to deepen the reflective capacity of those students through more structured and socially-mediated activity.

Findings from this research indicate that CM introduced within a socially supported and structured process can enable the shift from teacher reliance to student autonomy. It is also suggested that students do need structured and scaffolded activities in the area of Personal Development Planning (PDP), especially in reflective tasks, as they are often not sure how to approach this area of learning.

Key words: Concept mapping (CM); Personal Development Planning (PDP); reflection; meaning making; socially mediated activity. 


\section{Introduction}

The central purpose of education is to empower learners to take charge of their own meaning making. (Novak, 1998, p.9)

This paper proposes a way of supporting students' personal development with the use of a practical tool for Concept Mapping (CM) which lends itself well to the cyclical nature of Personal Development Planning (PDP).

The research reported here was part of a larger doctoral study by the author which used a range of research techniques including $\mathrm{CM}$ together with interviews, e-Portfolios, blogs and cultural learning journals. A CM technique developed by Novak and Cañas (2006) was adopted as a research instrument in this study. CM is explored in more detail here as it proved to be not only one means of gathering research data but at the same time - and most importantly - a powerful technique in supporting students' meaning-making (an unintended but significant outcome of this research). Jankowska (2009) states that the individual CM task can be a good vehicle for gaining insight into students' understanding of personal development.

Further analysis of the research data presented below drawn from follow-up interviews and student blogs casts more light on how CM can become even more effective when introduced as a socially mediated activity, especially when embedded within or followed by other PDP-related activities. This paper ends with an exploration of how a CM technique supported by socially mediated scaffolded activities can address the key elements of successful learner-centred education (discussed in the theoretical section).

\section{Use of CM as both a teaching and research tool}

Novak and Cañas (2006) describe concept maps as graphical tools for organising and representing knowledge in the form of diagrams with hierarchical nodes that contain concepts. Concepts are linked together with directional lines which are also labelled (indicating the relationship between concepts). Two or more concepts linked with words or phrases can make a proposition (a meaningful statement). The fact that the concepts are linked with the arrows and labelled is a distinctive feature which does not appear in other 
kinds of mind maps, but is an important step towards achieving fuller understanding of the knowledge that is available to a learner at a particular moment in time.

The student may hold both valid and invalid ideas (misconceptions) about a given subject and concept maps can be useful in revealing the incorrect assumptions, which then can be changed. Unless the learner is aware of the mistake, s/he cannot correct it. In order to investigate the learning in more detail it is important to show the concept maps made before and after the learning has taken place. This would make the changes in learning structures transparent and reveal the progress (or, unlikely but theoretically possible, regression or stagnation) in the students' knowledge of the subject. According to Novak (1998), Hay $(2007,2008)$ and others, concept maps have the value of accessing students' thinking or making learning visible as the teacher can actually 'see' what ideas the student has about a particular topic.

$\mathrm{CM}$ is also described as a research tool that captures learners' knowledge of a particular topic and has been used, especially in science, to picture students' representations of particular topics, diagnose the gaps in knowledge, monitor learning progress or, in fact, measure the impact of specific interventions (Hay, 2007, 2008; Jankowska, 2009; Jankowska et al., 2010; Kinchin et al., 2000; Kinchin et al., 2008a; Hay and Kinchin, 2006, 2008; Kinchin et al., 2008b).

CM can also be a useful reflective tool in PDP, making the process of acquiring the knowledge explicit. Providing structured, supported and contextualised opportunities for self-discovery and reflection on personal development within the curriculum can form congruent and holistic processes that engage students in a meaningful analysis of their developmental needs, building on their prior experience, recognising strengths and weaknesses, and looking into the future (Atlay et al., 2008).

$\mathrm{CM}$ requires individual analytical efforts and shifts responsibility for learning from the teacher to the learner (Peterson and Snyder, 1998). Moreover, there is a body of research evidence (Nygaard and Holtham, 2008, 2009) to show that students' active engagement in co-constructing knowledge as well as taking responsibility for their own learning and development is crucial to their achievement of better and wider learning outcomes. 


\section{The research}

The data presented in this paper come from a piece of research conducted on a postgraduate Communication in Business module (winter semester 2007/08). The research was ethically approved and all the students in this cohort were given a description of the study and consent forms.

\section{The sample}

The whole cohort was offered the opportunity to undertake CM on the topic of personal development. However, fewer than half of the students (53) completed concept maps at both the beginning and end of the module due to students' absence (either at the beginning or at the end of the semester), drop-out and some requests to be excluded from the study. The research concentrated on 32 participants covering the four most representative cultural backgrounds at the University of Bedfordshire (Chinese, African, Central Eastern European and British). All these students sketched concept maps both at the beginning and the end of the module, giving 64 altogether. The volunteers for the interviews were recruited from those 32 participants and included 11 students.

The research aimed to investigate cultural influences on experiences and representations of personal development as well as the value of concept maps in capturing these representations. This article concentrates on the latter only.

\section{The methodology}

The instruction on how to create a concept map was given to all the students simultaneously at a lecture and the researcher was available all the time to clarify any issues. The topic of CM was not informed by reference to the PDP agenda and its official definition - it was simply prompted with the question: What does personal development mean to you? (aimed at eliciting individual understandings). The students were given 30 minutes to complete this task. The concept maps obtained represent the general ideas students have on the topic of personal development. It is important to note that all the concepts came from the students - they were not elements given by the researcher for the participants to sort out. 
This research was conducted in a spirit of a qualitative, interpretive phenomenological enquiry (Cohen et al., 2008) which was deemed suitable for investigation of subjective perspectives on a very personal topic. Ontologically, interpretivism posits that reality is socially constructed, multiple and contextual (Ozanne and Hudson, 1989) and emphasises individual views and descriptions of how things are experienced first-hand by those involved. The discussion here predominantly concentrates on findings that refer to the use and value of concept maps.

The concept maps were analysed in two specific ways:

1. Content analysis of all 32 maps aimed at discovering more general inter-group tendencies (cultural comparisons).

2. The more detailed analysis of 11 pairs of maps (comparing the maps at the beginning and at the end of the module) aimed at gaining an insight into individual understandings and progression over time.

\section{Outcomes from the concept mapping task}

Some examples with interpretations are presented below.

\section{Example 1 - Student 3 (Central Eastern European):}

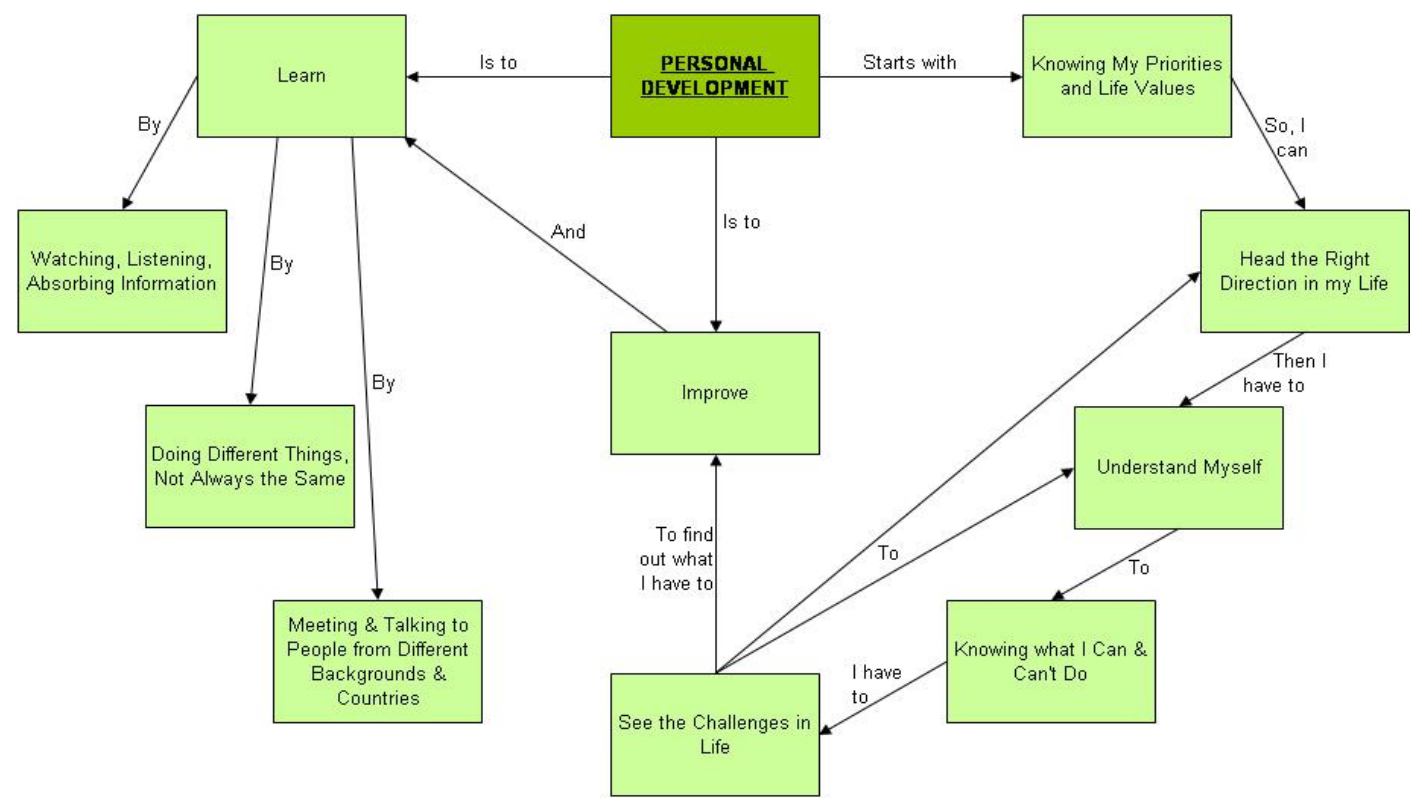

Figure 1a. Student 3: first map (at the beginning of the semester). 


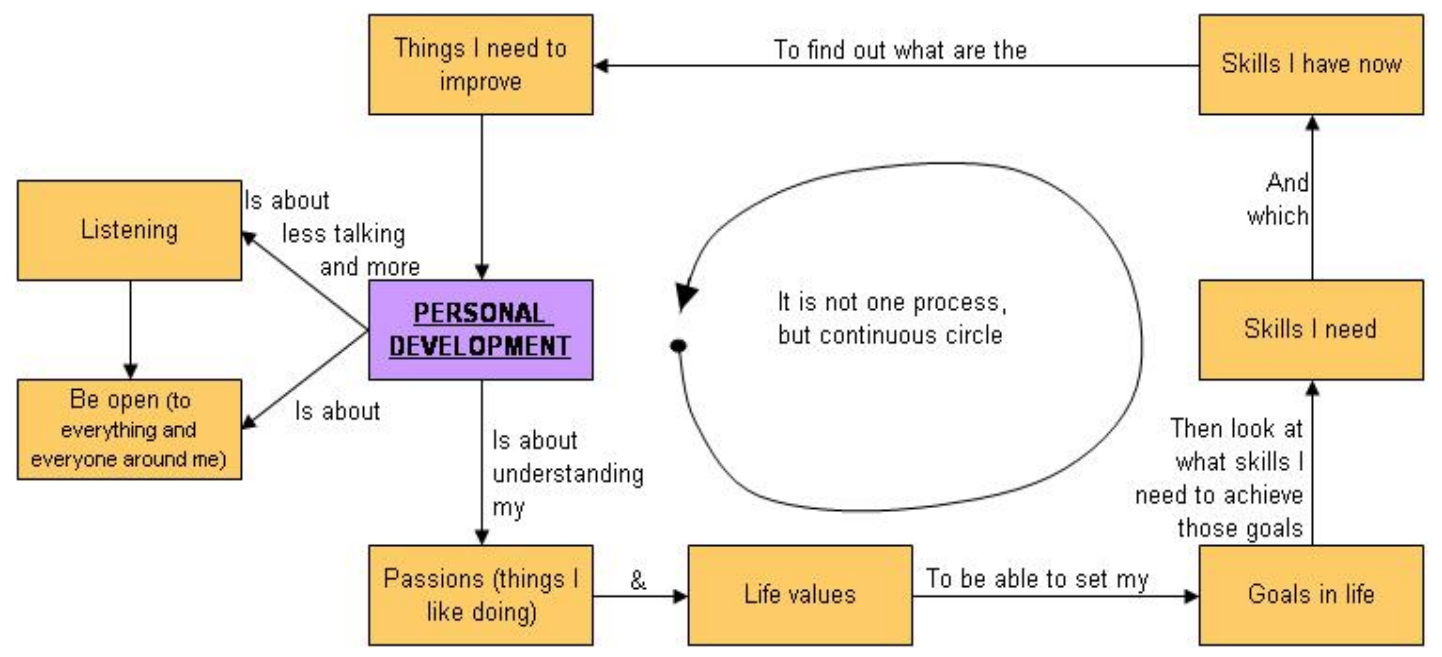

Figure 1b. Student 3: second map (at the end of the semester).

Student 3's maps contain similar concepts although they are expressed in a slightly different way. The second map's concepts are articulated in a more professional way (skills, goals, life values, passions instead of e.g. 'knowing what I can and can't do', 'head the right directions') as if the student had acquired a new way of expressing PDP ideas (much more resembling the way academics express them). The second map highlights personal development being a continuous process (articulated in the form of a circle). It also underlines the student's deeper understanding of the iterative nature of personal development processes and the need of continuous improvement (which was not so clearly formulated in her first map). Although the concept of self-awareness is not directly expressed in the second map, its elements are present in other concepts and links in the second map as well.

At first glance, it seems that there is no significant change in the structure and linkage of both maps but the second map represents a more developed, cohesive and clear vision of personal development as if the student has acquired both the knowledge to express her concepts and the ability to organise her conceptual vision in a more meaningful way. 
Example 2 - Student 4 (Chinese):

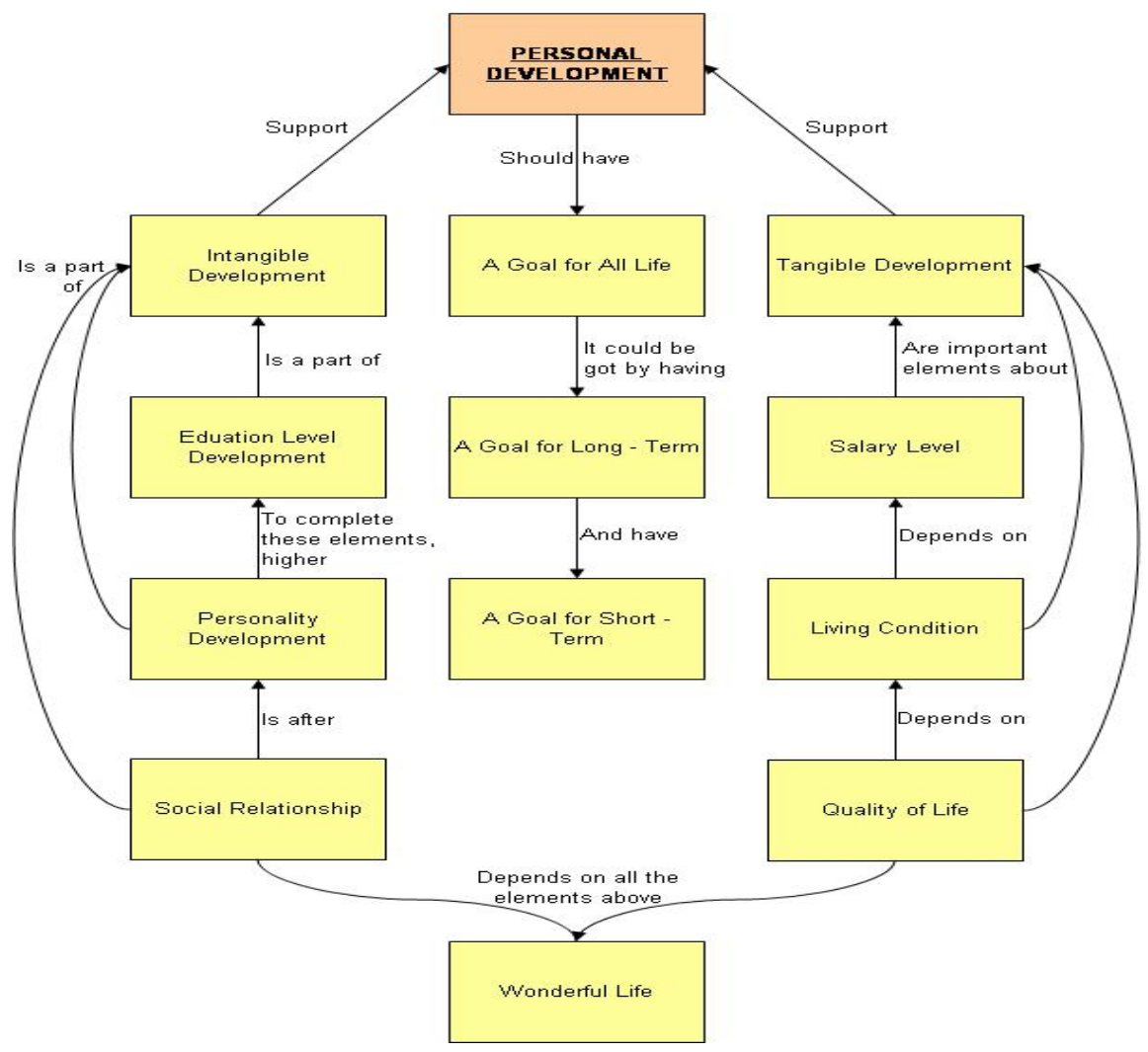

Figure 2a. Student 4: first map (beginning of the module).

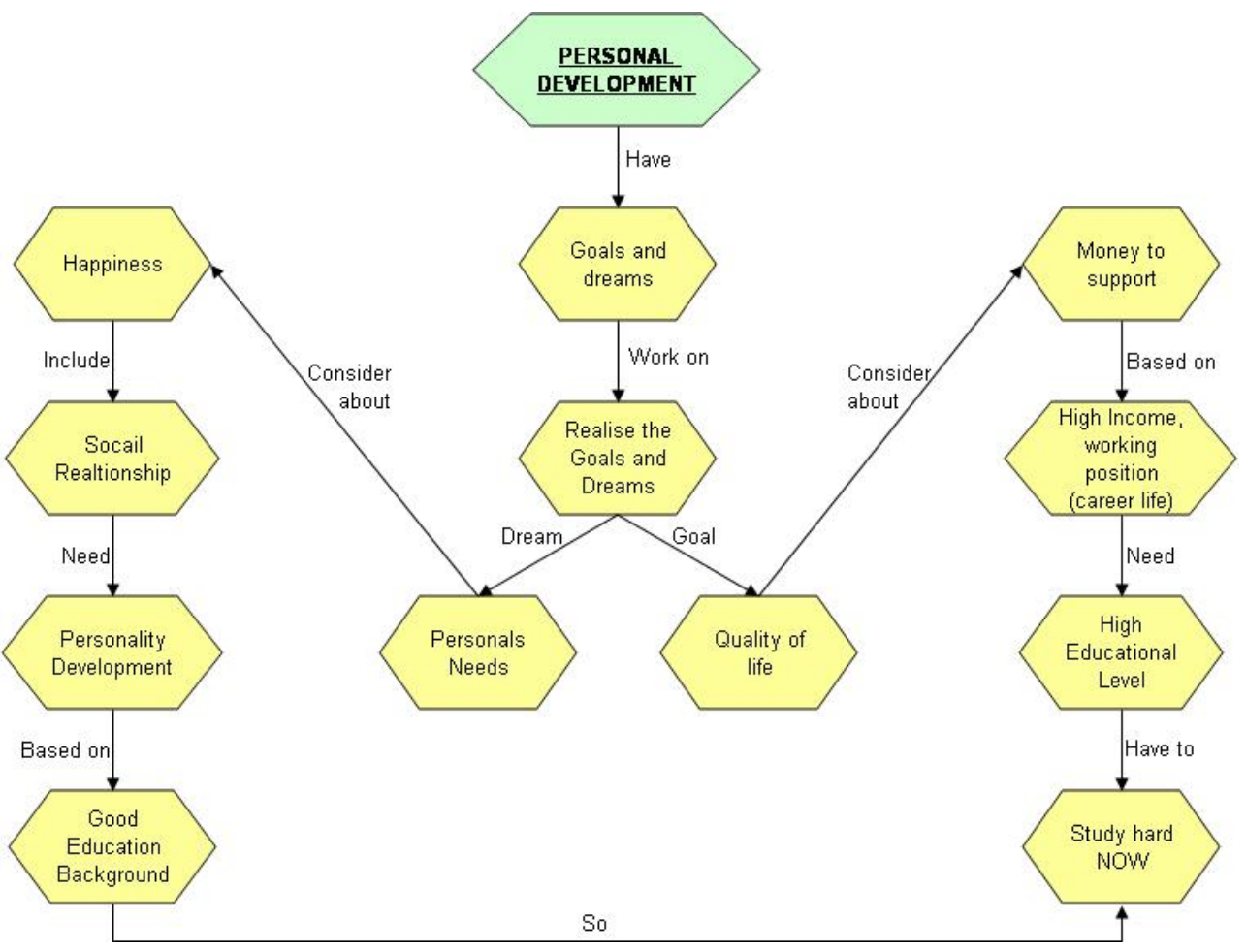

Figure 2a. Student 4: second map (end of the module). 
This student's maps are quite similar. There is no significant change in the structure and although she adds a few new concepts to her second map (e.g. 'happiness', 'personal needs', 'study hard NOW', 'high income working position (career life)'), they did not really contribute to her overall understanding of personal development.

This student made a clear division between 'intangible' and 'tangible' development. The concepts which can be classified as more 'soft' or personal are located on the left side of both maps, while the 'hard' ones - career and outcome oriented - are located on the right hand side of both maps. The concepts related to goals are located in the centre of both maps (disconnected from the rest of concepts in the first map). The second map has more links, with the most important between education and career - she clearly expresses the view that career progression is interlinked with studying, while in her previous map these two spheres were disconnected. Moreover, the centre of the map (goals) is connected with both left and right branches of the map. Instead of using 'intangible' and 'tangible' development, in her second map, she presents these 'soft' ideas on the left as her dreams and personal needs and the 'hard' ones on the right as goals leading to improvement in the quality of life. She identifies studying ('now') as a way of achieving and linking her dreams with goals.

Although according to Novak's (1998) typology of learning, this example would most likely be associated with rote learning, it can be argued that by introducing the linkage between the world of education and career the student made a slight move towards a deeper understanding of personal development. 
Example 3 - Student 9 (Tanzanian):

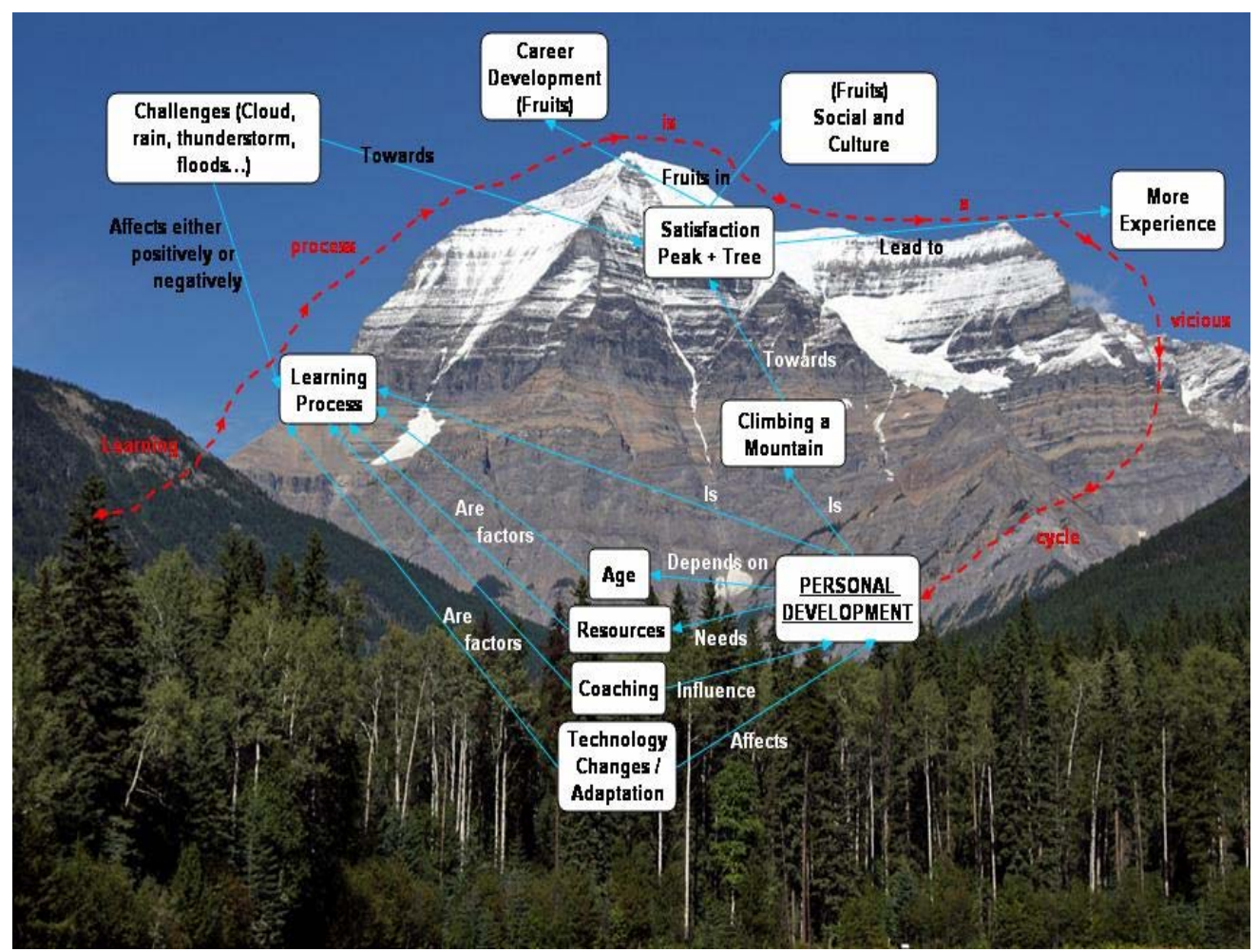

Figure 1a. Student 9*: first map (beginning of the module).

*Student 9 drew both her maps by hand. In order to transfer them to an electronic version the researcher had to map the data onto ready made pictures.

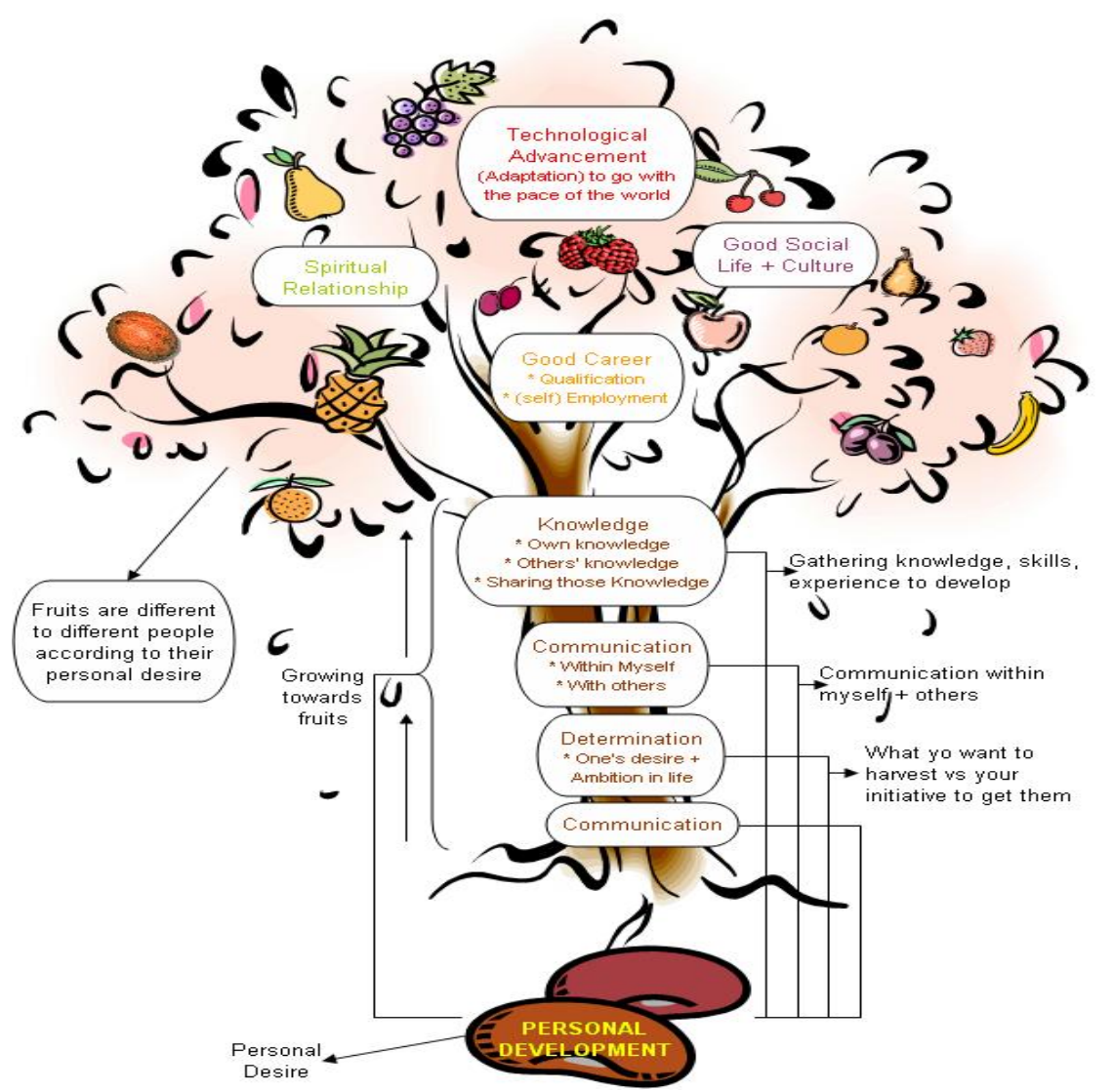

Figure 3b: Student 9 second map (end of the module). 
This student's maps pose a challenge for analysis as she did not follow the instructions. She used two different metaphors (drawings) for the two concept maps (hence some of the concepts differ) and came up with something in between a concept map and a drawing. Therefore it is more difficult to look at a structure or linkage of the 'maps' and classify them according to Novak's (1998) typologies (chain/spoke/net, non-learning/rotelearning/meaningful learning). However, the overall feel of understanding of personal development that this student gives is similar in both maps. Personal development is represented as a lengthy process, which starts metaphorically 'at the bottom' and leads to gathering personal fruit of satisfaction on completion of a cycle.

Her first map represents a mountain, where personal development is compared to the process of climbing. Reaching the peak is associated with obtaining satisfaction and bringing some 'fruit' ('career development' and 'social and culture satisfaction'). Personal development is also equated with learning processes which are influenced by factors such as age, resources, coaching and technology. On the way up there are challenges, represented in this map by clouds, rain, thunderstorms and floods. Reaching the top, however, is not the end of the journey and the whole process is seen by her as a cyclical one. Therefore after reaching one mountain top a person needs to set off for another one, and in this way more and more experience is being gathered.

The second map is a metaphor of growing a tree. Personal development here is planted with a seed of personal desire and the journey up to the top (gathering fruit) is fuelled with determination to achieve and ambition in life. Communication seems to be an important process facilitating the growth (both internal communication with self and with others) and on the way up one gathers knowledge, skills and experience (through exchange with others). The fruit are not only connected with a good career and social life and culture but also spiritual development and technological advancement. Interestingly, a career in this map is also related to qualifications and may mean employment or self-employment (no other student in this study mentioned self-employment). Technological advancement in her first map was one of the factors in the development, while in the second map it is a fruit of development (when one goes 'with the pace of the world'). There is no explicit notion of cyclical development in the second map, but this may be due to the metaphor used.

This student clearly has a vision and is open to opportunities, at the same time recognising the necessity to work hard in order to achieve. She also observes that 'fruits are different 
to different people according to their personal desire. Both maps are rich and represent a cohesive vision of personal development. The second map brought about some more professional language ('personal desire', 'ambition', 'communication', 'knowledge', 'skills', and 'experience') but lacked some of the important concepts from the first map, especially the idea of development being cyclical, the challenges on the way and some factors which play an important role in the process. From a personal development point of view these maps indicate the student's readiness to challenge instructions and come up with something that suits her better, while engaging her creativity and imagination. Creating such a metaphor involves the student in thinking a concept through and presenting it graphically to get the story across - all factors important in meaningful learning.

The qualitative content analysis of the sample casts some light on those aspects of personal development students concentrated on (some of which are neglected in the curricula). Many of the students' concept maps concentrated on particular areas of personal development (e.g. academic, career, social, etc.), omitting other aspects. It is possible that this happened because some students at this particular point in time were predominantly preoccupied with one area that needed to be developed.

\section{Follow-up interviews}

Eleven participants volunteered for individual in-depth, semi-structured, follow-up interviews. The aim of the interview was to elaborate on various aspects of personal development, approaches to learning and teaching, and career planning. The students were given an opportunity to talk about their personal constructs of personal development with reference to their concept maps. The interviews lasted on average 35 minutes and were conducted within the two weeks following the CM task. It was hoped that the data from the interviews would be illuminated with information obtained via blogs, cultural learning journals and e-Portfolios. Unfortunately not all of the eleven interviewees submitted the complementary data (not all the elements were compulsory and assessed within the module).

All but one of the eleven interviewees were very positive about $\mathrm{CM}$. The one exception claimed that her views of personal development were stable and would not be influenced by any PDP activities. Most saw it as a valuable experience as the task itself engaged them cognitively and gave them an opportunity to stop, reflect and talk about things they 
rarely focus on and verbalise in their daily life. Many students expressed the feeling of being so submerged in the task of CM that they became unaware of the time and surroundings (which Csikszentmihalyi (2000) refers to as the state of flow). They believed it would be a useful task in every student's course. Blog comments that came from the students interviewed further confirmed the relevance and value of the $\mathrm{CM}$ task:

Doing concepts maps has made me realise how I can better develop myself. () by writing everything down and interlinking them in anyway possible you get a bigger picture of what you have succeeded so far. () when doing it I found out that I had done many things and had many experiences which I had not realised until I did the concept map. () in the future I will definitely use a concept map in whatever it is. Using it for personal development is better though makes you think a lot about yourself and it will definitely help me think about the way I plan my future. I believe it already has, I didn't' really have a goal before but now I have chosen it and plan to succeed it. (BlogStudent7)

I learned a lot from concept maps, I will implement it in my future as a part of creative process and problem solving. I am an artist and doing concept maps is a great way of finding out about the associations in our minds, and this is an important part of creative process in art. Also doing concept maps can help to determine the important elements of any kind of decision in our lives... (). Doing concept maps makes this so much better, it allows me to go much deeply into the problem, I have an opportunity to explore all the elements of a certain decision, and also make links between them, later on I can study my own thoughts that I have put on paper a day before. (BlogStudent3)

Interviewees engaged in a two-step process. Firstly maps helped them think through and externalise their ideas about personal development, and secondly, the interview helped them further clarify their ideas. The findings indicate that CM promotes more positive insights for students when it is linked to social interaction and scaffolding (via structured reflection). 


\section{Moving CM forward through socially mediated structured approaches}

Constructivist learning theory provides the most important underpinning for CM. It indicates that people learn not only by memorising material (which would be defined as rote learning in Ausubel et al's (1978) and Novak's (1998) terms) but also, and more importantly, by integrating and organising new information into a pre-existing framework of knowledge (Phillips, 2000). Ausubel et al. (1978) underlined that the most important factor that influences learning is prior knowledge. Learners mediate and create their new comprehension of the subject matter on the basis of what they already know and believe, and internalise new material (Resnick, 1989).

However, learning cannot be viewed as an isolated activity. Vygotsky claimed that 'learning occurs through participation in social or culturally embedded experiences' (cited Raymond, 2000, p.176) and students need to be supported by more capable others 'scaffolds' (Raymond, 2000). The absence of guidance and social interaction leads to impediments in learning and development (Bransford et al., 2000): students may struggle in traversing the Zone of Proximal Development understood as '...the distance between the actual developmental level... and the level of potential development as determined through problem solving under adult guidance, or in collaboration with more capable others' (Vygotsky, 1978, p.86).

Reflection, understood as the learner's conscious effort and active engagement in the processing of new information and its integration with what is already acquired, is an important prerequisite to meaningful learning (Mezirow, 1990, 2000). The process of reflection is typically applied to relatively complicated or unstructured ideas for which there is not an obvious solution, and is largely based on the further processing of knowledge (Moon, 1999).

However, the research data commented on here as well as a growing body of research on difficulties around reflection and development of meta-cognitive skills (e.g. Bleakley, 2000; Clegg, 2004; Clegg and Bradley, 2006; Eraut, 2000; Tomlinson, 1999) indicate that there is a real need for structured reflective tools with clear instructions:

Ok, they say: reflect on your learning and understanding - but of what? Of what I've learned? Or what I gained for my future? Or how I learned it??? Or should I say 
what I will do in the future? And if yes, what should I focus on? How could I do it? I don't know! I would like to learn how can I improve my skills but I don't know what are the tools to do it. (Interview 3)

Reflection should not be seen as an irrelevant task introduced for a mere sake of doing it, but rather as a highly relevant activity linked to real life experiences and learning aims that is valued both by staff and students. According to McKenzie (2000, p.2) in scaffolding structure is the key component - 'without clear structure and precisely stated expectations, many students are vulnerable to a kind of educational 'wanderlust' that pulls them afield'.

This study seems to demonstrate that socially mediated CM followed by other related developmental activities provides a scaffold for students' reflection. CM combined with relevant socially mediated activities, such as peer discussions framed by a set of reflective questions (as proposed below), can provide a structure and support for personalised learning, create a genuinely learner-centred approach, and promote meaningful and transformative learning.

In a typically large classroom the opportunities for personalised dialogue with a tutor are scarce. Therefore, a carefully structured group task could prompt students to think about elements currently missing from their concept maps as well as reinforce elements of strengths and address associated issues in order to derive the full benefits intended by the PDP agenda. In an ideal case scenario, the CM should be followed by group mediated discussions with other follow-up activities structured with students' personal development in mind, running throughout a semester, module, year or course of studies, and summarised with another CM task. This would provide both a record of personal development (from the first to the last concept map) and reinforce the cyclical nature of PDP, providing students with an abundance of developmental opportunities on the way.

The questions suggested here (modified but based on the questions from semi-structured interviews conducted for this research) are indicative examples that lend themselves to customisation and personalisation (tutors should be encouraged to apply them at different levels of granularity, adapting them to suit the specific needs of students within subject or practice areas, as not all of them may be relevant to each student). If these questions are asked in a spirit of appreciative inquiry (Cooperrider, 1990; Cooperrider and Srivastva,1987) this has the effect of creating a psychologically safe and positive 
environment for sharing concepts with a view to appreciating in value whatever is positive in students' maps - i.e. identifying and critically appreciating strengths, and working from positions of self-efficacy beliefs to address development needs. It involves tutors stipulating that there are no right or wrong answers, simply an attempt to discover effective ways of moving forward from current concepts and practices.

The questions listed below can elicit valuable responses:

1. What areas of personal development did you focus on? (Which ones are the most important and why? What areas did your peers concentrate on?)

2. Is there anything else missing from your map that might be important?

3. What are your strengths and weaknesses?

4. What are your interests, aspirations, priorities in life? (What motivates you?)

5. What goals are important for you to achieve?

6. How do you make sure that you stay on track and achieve what you have planned?

7. What opportunities (activities in learning, work, extra-curricular options, and support) could you engage with to achieve your goals?

8. What would enable you to achieve your best results?

Questions such as these act as prompts for students' personalised learning and development, but in socially mediated situations they can be tailored to specific timely topics that need to be addressed. An integrated, cyclical process can instigate deeper reflection at appropriate stages (e.g. at the beginning and the end of semester, or year). As highlighted before there should be follow-up opportunities for CM and discussion of the outcomes and the process itself. Kumar $(2007,2009)$ provides further examples of practical activities that are tried and tested with different groups of students, and help to generate, clarify or test out aspirations and achieve more effective results. These activities can be tailored and embedded in specific units but ideally should be allied in a way that creates a coherent, structured process which supports students' development and improves reflective practice. 


\section{Conclusions}

Learning is a process and as such requires conscious effort in making connections between existing (prior) knowledge, current experiences and future events (Atlay et al., 2008). CM itself can be a useful reflective tool, which helps reveal students' knowledge and understandings at a particular time. Based on the presented research data, theory and the university experiences with PDP however, the author suggests that CM could serve as a basis for further socially mediated activities (be it peer discussions, student-tutor communications, career guidance or reflective narratives) that move students' thinking towards deeper understanding and can be a driver for personal change. Moreover, such discussion or group activity should be structured in a way that points students towards all important areas of personal development.

The research suggests that effective teaching starts with understanding where the students are in their development (Freire, 1998; Bransford et al., 2000). This has become one feature of the revised curriculum at our university, together with its 'SOARing to Success' counterpoint - students understanding themselves: who they are and who they want to be (Kumar, 2007, 2009, 2010). SOAR stands for Self, Opportunities, Aspirations and Results and is an integrated and cyclical process underpinning PDP with practical tasks designed to raise the awareness of self and opportunity, as well clarify or test out aspirations and achieve more effective results (Kumar, 2007). As higher education faces the challenge of educating a larger and more diverse body of students with less resource (e.g. Caroll and Ryan, 2005; Robinson-Pant, 2005; Trahar, 2007), it is even more important to provide both personal and social constructionist opportunities that equip students with tools that enhance self-awareness in the light of social and external frames of reference - tools such as self-audits that will further drive self-development and selfmanagement.

This paper has presented a practical CM tool for personal development purposes. Personal Development Planning in its own nature is cyclical and involves learning, doing, reflecting and recording. $\mathrm{CM}$ instigates reflection and allows for recording of its outcomes it is a tangible representation of students' understanding of a given subject at a particular point in time and can be stored (in e-Portfolio for example) for future reference. 
The proposed process of combining CM with other socially mediated tasks (such as the suggested reflective questions) has been developed as a practical outcome of the conducted research combined with conceptual insights, and can be easily adjusted to the specific students' needs and particular subjects. Further research is needed to investigate the value of this approach and gain a better in-depth understanding of how the repeated task of CM supported by socially mediated, structured PDP activities, can enhance students' development.

\section{Acknowledgement}

This paper is an outcome of the National Action Research Network on researching and evaluating Personal Development Planning and e-Portfolio practice project (2007-2010). The project was led by the University of Bolton in association with the University of Worcester and Centre for Recording Achievement, and in national collaboration with the University of Bedfordshire, Bournemouth University and University of Bradford. The project was funded by the Higher Education Academy, National Teaching Fellowship Project strand. More details about the project can be found at: http://www.recordingachievement.org/research/narn-tree.html.

I am immensely grateful to Tricia Smart (Senior Lecturer in Language and Communication, Business School, University of Bedfordshire) who granted access to her students for the research purposes. A debt of gratitude is due to all those who participated in this study as well as colleagues with whom many debates about PDP, CM and cultural aspects of my research were held. Special acknowledgements to Arti Kumar who is wholeheartedly passionate about making a difference to our students, Dr Alfredo Gaitan and Dr Andrea Raiker whose advice, support and encouragement has been invaluable.

\section{References}

Atlay, M., Gaitan, A. and Kumar, A. (2008) 'Stimulating learning - creating CRe8', in Nygaard, C. and Holtham C. (eds.). Understanding learner-centred higher education. Copenhagen: Copenhagen Business School Press, pp. 231-250. 
Ausubel, D.P., Novak, J.D. and Hanesian, H. (1978) Educational psychology: a cognitive view. New York: Holt, Rinehart and Winston.

Bleakley, A. (2000) 'Writing with invisible ink: narrative confessionalism and reflective practice', Reflective Practice, 1(1), pp. 11-24.

Bransford, J., Brown, A. and Cocking, R. (2000) How people learn: brain, mind, experience and school. Washington, DC: National Academy Press.

Carroll, J. and Ryan, J. (eds.) (2005) Teaching international students: improving learning for all. London: Routledge.

Clegg, S. (2004) 'Critical readings: progress files and the production of the autonomous learner', Teaching in Higher Education, 9(3), pp. 287-298.

Clegg, S. and Bradley, S. (2006) 'The implementation of progress files in higher education: reflection as national policy', Higher Education, 51(4), pp. 465-486.

Cohen, L., Manion, L. and Morrison, K. (2008) Research methods in education. $6^{\text {th }}$ edn. London and New York: Routledge.

Cooperrider, D. (1990) 'Positive image, positive action: the affirmative basis of organizing', in Srivastva, S. and Cooperrider, D.L. (eds.) Appreciative management and leadership: the power of positive thought and action in organizations. San Francisco: Jossey-Bass, pp. 91-125.

Cooperrider, D. and Srivastva, S. (1987) 'Appreciative inquiry', in Woodman, R.W. and Pasmore, W.A. (eds.) Research in organizational change and development. Vol. 1. Greenwich, CT: JAI, pp. 129-169.

Csikszentmihalyi, M. (2000) Beyond boredom and anxiety: experiencing flow in work and play. San Francisco: Jossey-Bass Publishers.

Eraut, M. (2000) 'Non-formal learning and tacit knowledge in professional work', British Journal of Educational Psychology, 70(1), pp. 113-36. 
Freire, P. (1998) 'Sixth letter: on the relationship between the educator and the learners', in Freire, P. (ed.) Teachers as cultural workers: letters to those who dare teach. Boulder, Colorado: Westview Press.

Hay, D.B. (2007) 'Using concept maps to measure deep, surface and non-learning outcomes', Studies in Higher Education, 32(1), pp. 39-57.

Hay, D.B. (2008) 'Developing dialogical concept mapping as an e-learning technology', British Journal of Educational Technology, 39(6), pp. 1057-1060.

Hay, D.B. and Kinchin, I.M. (2006) 'Using Concept maps to reveal conceptual typologies', Emerald Education and Training, 48(2-3), pp. 127-142.

Hay, D.B. and Kinchin, I.M. (2008) 'Using concept mapping to measure learning quality', Education and Training, 50(2), pp. 167-182.

Jankowska, M. (2009) 'CMing technique as a vehicle for gaining insight into students' understanding of personal development', ICERI 2009 International Conference of Education Research and Innovation. Madrid, Spain 16-18 November. ICERI 2009 proceedings, ISBN: 978-84-613-2953-3.

Jankowska, M., Gaitan, A. and Atlay, M. (2010) 'Who are you and what is your destination? Evaluation of an entry point and the role of cultural differences in Personal Development Planning', Problemy Profesjologii, 2, Zielona Gora.

Kinchin, I.M., Hay, D.B. and Adams, A. (2000) 'How a qualitative approach to concept map analysis can be used to aid learning by illustrating patterns of conceptual development', Educational Research, 42(1), pp. 43-57.

Kinchin, I.M., Cabot, L. B. and Hay, D.B. (2008a) 'Visualising expertise: towards an authentic pedagogy for higher education', Teaching in Higher Education, 13(3), pp. 315-326.

Kinchin, I.M., Lygo-Baker, S. and Hay, D.B. (2008b) 'Universities as centres of nonlearning', Studies in Higher Education, 33(1), pp. 89-103. 
Kumar, A. (2007) Personal, academic and career development in higher education SOARing to success. London and New York: Routledge, Taylor and Francis.

Kumar, A. (2009) 'Using assessment centre approaches to improve students' learning', Nygaard, C., Holtham, C. and Hawthorn, N. (eds.) Improving students' learning outcomes. Frederiksberg, Denmark: CBS Press.

Kumar, A. (2010) 'SOARing for employability: can assessment centre approaches engage students?' in Atlay, M. (ed.) Creating bridges: a collection of articles relating to implementing the Curriculum Review 2008 (CRe8) from practitioners across the University of Bedfordshire. University of Bedfordshire internal publication, pp. 84103.

McKenzie, J. (2000) Scaffolding for success. Available at: http://fno.org/dec99/scaffold.html (Accessed: 7 May 2010).

Mezirow, J. (1990) Fostering critical reflection in adulthood: a guide to transformative and emancipatory learning. San Francisco: Jossey-Bass.

Mezirow, J. (2000) Learning as transformation: critical perspectives on a theory in progress. San Francisco: Jossey-Bass.

Moon, J.A. (1999) Reflection in learning and professional development: theory and practice. London: Kogan Page.

Novak, J.D. (1998) Learning, creating and using knowledge: concept maps as facilitative tools in schools and corporations. Mahwah, NJ: Lawrence Erlbaum Associates.

Novak, J.D. and Cañas, A.J. (2006) The theory underlying maps and how to construct them. Technical Report IHMC CmapTools 2006-01 Rev 01-2008, Florida Institute for Human and Machine Cognition, 2008. Available at: http://cmap.ihmc.us/Publications/ResearchPapers/TheoryUnderlyingConceptMaps. pdf (Accessed: 6 November 2010). 
Nygaard, C. and Holtham, C. (eds.) (2008) Understanding learning-centred higher education. Copenhagen: Copenhagen Business School Press.

Nygaard, C. and Holtham, C. (eds.) (2009) Improving students' learning outcomes. Copenhagen: Copenhagen Business School Press.

Ozanne, J.L. and Hudson, L.A. (1989) 'Exploring diversity in consumer research', in Hirschman, E. (ed.) Interpretive consumer research. Provo, UT: Association for Consumer.

Peterson, A. and Snyder, J. (1998) 'Using concept maps to teach social problem analysis', Annual Meeting of the Society for the Study of Social Problems. Columbus State Community College, San Francisco 20 August, pp. 5-28.

Phillips, D.C. (ed.) (2000) Constructivism in education: opinions and second opinions on controversial issues. The National Society for the Study of Education. Chicago: University of Chicago Press.

Raymond, E. (2000) Cognitive characteristics. Learners with mild disabilities. Needham Heights, MA: Allyn and Bacon, A Pearson Education Company, pp. 169-201.

Resnick, L.B. (ed.) (1989) Knowing, learning and instruction. Hillsdale NJ: Lawrence Erlbaum Associates.

Robinson-Pant, A. (2005) Cross-cultural perspectives on educational research. Buckingham: Open University Press.

Tomlinson, P. (1999) 'Conscious reflection and implicit learning in teacher preparation. Part 1: recent light on an old issue', Oxford Review of Education, 25(4), pp. 533-44.

Trahar, S. (2007) Teaching and learning: the international higher education landscape some theories and working practices. Discussion paper in Discussions in Education Series, Subject Centre for Education ESCalate, The Higher Education Academy. Available at: http://escalate.ac.uk/downloads/3559.pdf (Accessed: 22 December 2009). 
Vygotsky, L.S. (1978) Mind in society: the development of higher psychological processes. Cambridge: Harvard University Press.

\section{Author details}

Maja Jankowska is a CETL Research Fellow and a member of the Action Research Consortium (ARC) established at the University of Bedfordshire in 2008. She works with other staff to help and support the development of a pedagogic research culture across the university. Maja is currently nearing completion of her PhD. Her interests are in PDP, cultural aspects of teaching and learning, internalisation of education, creativity, meaningful learning and social learning spaces. 